e-1

Advances in Animal Biosciences (2016), 7:1, pp e-1 (c) The Animal Consortium 2016

doi:10.1017/S2040470016000078

\title{
Corrigendum
}

\section{Effects of concentrate nitrogen levels on production performance and nutrient digestibility of lactating dairy cows fed zero-grazed grass and concentrate diets - CORRIGENDUM

\author{
D Hynes, S Stergiadis, T Yan
}

doi:10.1017/S2040470016000042, Published by Cambridge University Press 3 March 2016.

The original version of this summary was published with the author S. Stergiadis's name incorrectly spelled. The correct spelling is S. Stergiadis. The name has been corrected in the online version.

\section{Reference}

Hynes D, Stergiadas S and Yan T 2016. Effects of concentrate nitrogen levels on production performance and nutrient digestibility of lactating dairy cows fed zero-grazed grass and concentrate diets. Advances in Animal Biosciences 7, 116. 